\title{
O CINEMA SEM IMAGENS
}

paulo de andrade

UFMG

\begin{abstract}
RESU M O
A obra cinematográfica de Marguerite Duras, praticamente desconhecida pelo grande público, estabelece intricadas relações com sua obra literária, ao promover a indiscernibilidade entre os dois campos, sem, contudo, instituir qualquer tipo de subordinação de um ao outro. $\mathrm{O}$ processo de criação do filme Le camion, de 1977, aponta para outras possibilidades de se pensar o cinema e a literatura.
\end{abstract}

PALAVRAS - CHAVE

Marguerite Duras, escrita, cinema

para D.,

que sonhou com a impossibilidade.

Você olhará o que está vendo. Mas olhará absolutamente. Você tentará olhar até a extinção de seu olhar, até sua própria cegueira e através dela deverá tentar ainda olhar. Até o fim.

Marguerite Duras

Faço filmes para ocupar meu tempo. Se eu tivesse a força de nada fazer, nada faria.É porque não tenho a força de me ocupar com nada que faço filmes. Por nenhuma outra razão. É o que de mais verdadeiro posso dizer sobre meu empreendimento. ${ }^{1}$

Ocupar-se com nada: talvez o cinema de Marguerite Duras não chegue jamais a receber uma definição mais precisa. Esses filmes desaparecidos, soltos, aos farrapos, nunca vistos, feitos sem contrato, não chegam sequer a configurar um apêndice de sua obra escrita. Nem mesmo uma ocupação paralela à escrita. Quantos saberão da existência de seu cinema? Trata-se, sim, da força de nada fazer, essa força insustentável, que não se pode chegar a ter, que é preciso daí se retirar: o cinema por nada — não é, entretanto, uma troca, uma substituição, mas uma condição maior, irrevogável: o cinema, aqui, exige isso, não é mais do que isso, ocupar-se com nada.

É preciso notar, contudo, que essa paixão pelo nada atravessa, também, os livros de Duras, convidando-os, de certa forma, a buscar na imagem essa planície desolada, desabitada, onde nada se acrescenta a nada: "Então, vejam, escrevo por nada. Escrevo como é preciso escrever, parece-me. Escrevo por nada." ${ }^{2}$ Talvez pudéssemos aqui pensar

${ }^{1}$ Duras, Porte. Les lieux de Marguerite Duras, p.11.

${ }^{2}$ Duras. La vie matérielle, p.59. 
que, nessa obra, a escrita é assolada por um desejo da imagem, encontrando no cinema a sua realização plena e cabal, já que aí ela desaparece, entra no movimento de sua própria dispersão. E sabemos, com Blanchot, que "a literatura vai para si mesma, para sua essência, que é o seu desaparecimento", ${ }^{3}$ ou, como nos diz a própria Duras, "ela vai muito longe, a escrita... Até se acabar". ${ }^{4}$ Então, se o cinema aqui não se apresenta com a afirmação de uma obra autônoma, apartado da escrita, ele também não pode ser tomado como refugo dela, ao contrário, vê-se aí enredado até a perdição — de ambos: "Não sei se encontrei o cinema. Eu o fiz. Para os profissionais, o cinema que faço não existe."

Sim, um cinema que não existe, uma literatura destruída, acuada em seu limite — "A dúvida é escrever." ${ }^{6} \mathrm{E}$, ainda assim, feito, escrita. Esse paradoxo vive mesmo no ponto central da obra, aquele mais esquivo, que se confunde com o seu fim último e sua origem mais original, aquele que, segundo Blanchot, o artista deve buscar acima de tudo, e que o conduz exatamente a uma ausência de obra, a qual, no entanto, só pode ser produzida a partir da própria obra:

Escrever é produzir a ausência de obra (a desocupação). Ou ainda: escrever é a ausência de obra tal que ela produz-se através da obra e atravessando-a. Escrever como desocupação (no sentido ativo dessa palavra) é o jogo insensato, o risco entre razão e desrazão.?

Jogo arriscado e insensato, escrever reside (resiste) sobre o risco: entre a razão e a desrazão. Risco, contudo, que é o próprio traço: traço da escrita, da ausência. Produzir a ausência, portanto, difere radicalmente de deparar-se com ela, como se fosse dada a priori. Antes, é uma passividade literal, um estar sujeito sem complemento, é a construção desse lugar desocupado, quando o ofício de escrever atinge o "nãotrabalho", isto é, quando "trabalhar é fazer o vazio para deixar vir o imprevisível, a evidência. Abandonar, depois retomar, voltar atrás, estar inconsolável tanto por ter deixado vir quanto por ter abandonado. Desobstruir de si”. ${ }^{8}$ E nessa desobstrução, nesse vazio que a palavra cava, sobrevém a sua errância, a sua perdição:

Como não voltar? É preciso perder-se. Não sei. Você aprenderá. Eu queria uma indicação para me perder. É preciso não ter segunda intenção, dispor-se a não mais reconhecer nada do que se conhece, dirigir seus passos ao ponto mais hostil do horizonte, uma espécie de vasta extensão de pântanos que mil taludes atravessam em todos os sentidos não se sabe por quê. ${ }^{9}$

\footnotetext{
${ }^{3}$ Blanchot. O livro por vir, p.205.

${ }^{4}$ Duras. Écrire, p.30.

${ }^{5}$ Duras. Les yeux verts, p.43.

${ }^{6}$ Duras. Écrire, p.22.

${ }^{7}$ Blanchot. L'entretien infini, p.622-3. É importante aqui atentarmos para a palavra désceuvrement, utilizada por Blanchot e que traduzimos por desocupação. Nas traduções para o português, tem-se preferido ociosidade. Apesar de desocupação não estabelecer, como no original francês, um jogo de palavras com obra (œuvre / désœuvrement), ela mantém os sentido de "ociosidade", "sem ofício", "livre", e também de "esvaziamento", como quando se diz "desocupação de um imóvel", reiterado aí pelo prefixo des- ("separação, transformação, intensidade, ação contrária, negação, privação") que se encontra igualmente no original. Preferimos, assim, mesmo correndo o risco de cair em sulcos costumeiros da língua, estar em meio a seu fluxo-e-refluxo (como a palavra em francês está) a, fugindo dele, forjar algo como o neologismo desobramento.

${ }^{8}$ DurAs. Les yeux verts, p. 17.

${ }^{9}$ DuRAs. Le vice-consul, p.849.
} 
Sim, é disso que se trata - escrever, perder-se: dirigir-se ao ponto mais hostil do horizonte e descobrir que "o desejo secreto da palavra é o de se perder" ${ }^{10}$ Não lograr outra coisa, não ter outra intenção a não ser a de escrever, seguir a indicação: perder-se. E Duras vai mais além: perde também a própria escrita, para que ela, irreconhecível, estrangeira, converta-se nessa espécie de paisagem alagada, movediça, em que a terra perde-se em água, lodo, e todo caminho faz-se desvio, corta para um outro, para todos os outros, para nenhum. Mas, na obra de Duras, que indicação seria essa? Que palavra, ressonando a palavra-ausência, leva aí à perdição? De qual doença padece sua escrita, roubando-lhe a voz, o desenho das letras, e manchando com um branco espesso o espaço entre as frases? Poderíamos apressar-nos em responder que a escrita sofre da doença da escrita. Mas parece haver um outro nome: não é esse silêncio extenuado e inesgotável buscado na imagem, nesse ocupar-se com nada, nessa desocupação da escrita que é, para Duras, o cinema?

Mas de que cinema se trata? Não do cinema como comumente o entendemos. Sem dúvida, daquele que se afasta do filme; que, de alguma maneira, pode prescindir de sua própria filmagem; daquele que se realiza antes das imagens capturadas ou que escapa ao campo de visão da câmera. Porque, de fato, para Duras, "o cinema só existe como função fundamental", ${ }^{11}$ não se reduzindo às obras fílmicas nem a nenhum procedimento de linguagem característico, mas como uma espécie de arte do fracasso, que deve lutar pelo seu fracasso, contra o filme, uma vez que

o cinema aprisiona o texto, fere de morte sua descendência: o imaginário.

Aí está sua própria virtude: fechar. Aprisionar o imaginário.

Essa prisão, esse fechamento chama-se: filme.

Bom ou ruim, sublime ou execrável, o filme representa essa prisão definitiva. ${ }^{12}$

Não é sem razão que o cinema de Duras irá procurar, de todas as maneiras, afastar-se do filme que, apesar de constituir-se de imagens, forclui o próprio imaginário. Mas como será possível imaginar um cinema que, para garantir essa abertura ao imaginário, possa desfazer-se das imagens fílmicas, como se elas fossem apenas uma ponte, um veículo capaz de transportar o cinema, mas que deveriam, de certo modo, ser deixadas de lado, abandonadas? Em Le camion, filme de 1977, Duras alcança, de maneira transparente, um cinema que, afastando-se do filme, aproxima-se do texto, sem ser, contudo, "literatura filmada".

Enquanto procurava uma atriz para protagonizar Le camion, Duras ainda pensava em "filmar a história" que havia escrito, embora isso, o tempo todo, causasse nela um certo "mal-estar", uma vez que já havia passado por experiências de intensa radicalidade com o cinema, sobretudo com seu filme quase que imediatamente anterior a Le camion - Son nom de Venise dans Calcutta désert, de 1976 - , em que Duras filma, por duas longas horas, um antigo palácio, sua fachada, seu jardim — que fora, em parte, cenário de India song, um outro filme, de 1975 — , seu interior vazio e em ruínas, tudo sem a mínima presença de atores, apenas escadas, portas, paredes carcomidas, janelas quebradas: uma suntuosa paisagem de decadência e abandono.

${ }^{10}$ Blanchot. A parte do fogo, p.22.

${ }^{11}$ DurAs. Entretien avec Michelle Porte, p.96.

${ }^{12}$ DuRAs. Deuxième projet, p.75. 
Como nenhuma das atrizes consultadas para Le camion estava disponível, Duras chega a cogitar fazer, ela própria, a personagem, uma mulher de meia idade que pede carona numa estrada à beira-mar. Mas, agora por motivos materiais (o filme se passaria no interior da cabine do caminhão e o inverno rigoroso dificultaria muito a filmagem), acaba novamente se deparando com a impossibilidade de sua realização. Curiosamente, o filme só se abrirá para sua possibilidade no instante em que Duras desiste de "fazê-lo": "Tive insônia certa noite e depois eu me disse: não vou fazer o filme, vou contá-lo — fiquei completamente livre quando descobri isso - , ou seja, vou contar o que teria sido o filme se ele tivesse sido feito." ${ }^{\prime 3}$

A partir daí, o cinema poderá caminhar para a sua feitura: quando ele deixa de ser um filme que "será feito" para se tornar apenas um filme que "será contado". Essa liberdade, essa passagem produzirá uma transformação radical na concepção do filme e em seu texto: a imagem cinematográfica irá limitar-se a mostrar somente uma sala (denominada de câmara escura ou câmara de leitura) onde se encontram Duras e Gérard Depardieu, sentados à mesa, lendo a história do filme (sem nenhum ensaio prévio), com exceção dos momentos em off, em que vemos um caminhão atravessar uma paisagem francesa de zona industrial, sem jamais vermos o motorista ou qualquer outra presença humana (o que por si só subtrai à imagem sua suposta função representativa, de mera ilustração do texto, pois há entre eles uma fratura e uma relação de autonomia).

O filme, então, é lido. Contudo, sua leitura será marcada por um outro tempo que não o da realização: o condicional - uma vez que não se trata aqui de um filme, mas da leitura daquilo que poderia ser o filme. Ao publicar o texto de Le camion, Duras aponta para a importância do condicional na estrutura do filme, citando, como epígrafe, as características de seu emprego:

É por tradição que se considera o condicional como um modo. Pode-se estimar que ele é, na realidade, um tempo (um futuro hipotético) do modo indicativo.

O condicional propriamente dito exprime um fato eventual ou irreal cuja realização é vista como a conseqüência de um fato suposto, de uma condição. (...)

[É empregado também] para indicar uma simples imaginação, transportando de certa forma os acontecimentos para o campo da ficção (em particular um condicional introdutório, empregado pelas crianças nas suas propostas de brincadeiras)..$^{14}$

O condicional é, de fato, um tempo agenciador de tempos. Na língua portuguesa, ele corresponde ao nosso "futuro do pretérito" (no francês, é também chamado de "futuro anterior"), nome que torna clara a tensão entre tempos aparentemente opostos e aponta para a existência de um futuro-não-realizado-de-um-passado, ou, ainda mais longe, do futuro-em-potência que habita todo passado, independente de sua realização. Essa outra ordem de relação temporal é, sem dúvida, aquela implicada nos meandros da criação, da "imaginação", que transporta os acontecimentos para o campo da pura potência (aqui entendida fora da dicotomia possível/impossível, ou, melhor dizendo, como um terceiro termo que só acolhe a possibilidade atravessada pela impossibilidade). Esse campo, sabemos, é por excelência o da ficção, do jogo, da narrativa-introdutória, do cinema-criança:

${ }^{13}$ Duras. Entretien avec Michelle Porte, p.86.

${ }^{14}$ Grevisse citado por Duras. Le camion, p.7. 
Na gramática Grevisse, diz-se que o futuro do pretérito é o condicional introdutório empregado pelas crianças nas suas propostas de brincadeiras. As crianças dizem: você ia ser um pirata, você é um pirata, você ia ser um caminhão, eles se tornam o caminhão; e o futuro do pretérito é o único tempo que traduz o jogo das crianças: total. Seu cinema. ${ }^{15}$

Assim, de certa forma, o futuro do pretérito condensa essa ambição do cinema de Duras: atingir o ponto inaugural das imagens, o ponto originário das palavras, uma espécie de nascente - não o mito de retorno à origem, mas a cena-palavra começante (para ficarmos com o termo de Blanchot) ${ }^{16}$ quando voltar ao início é já lançar-se no recomeço, no futuro de uma linguagem sem precedentes, zerada, imobilizada no fulgor de seu nascimento: "No cinema, como tenho uma espécie de desprezo pelo cinema já feito, enfim, pela maior parte do cinema já feito, eu gostaria de retomá-lo do zero, em uma gramática muito primitiva... muito simples, muito primária quase: não mover, recomeçar tudo."17

Essa busca de um cinema primitivo, com uma sintaxe rarefeita, tomado em sua forma condicional, irá contaminar, no caso de Le camion, a escrita do filme, em seu sentido amplo. Não somente o tempo verbal do texto será transformado - pontuando aí a condição em potência do filme:

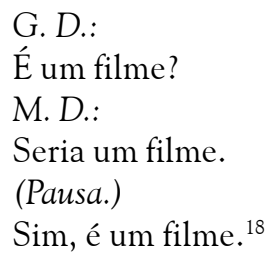

—, como também o grande apelo feito à imagem, ao olhar, fortemente marcado e reiterado, é reservado, reduzido às palavras, pois são elas as guardiãs do imaginário: assim, a imagem não é nem representada nem apresentada, ela é evocada pela leitura do texto, ela permanece aí nesse lugar de uma promessa:

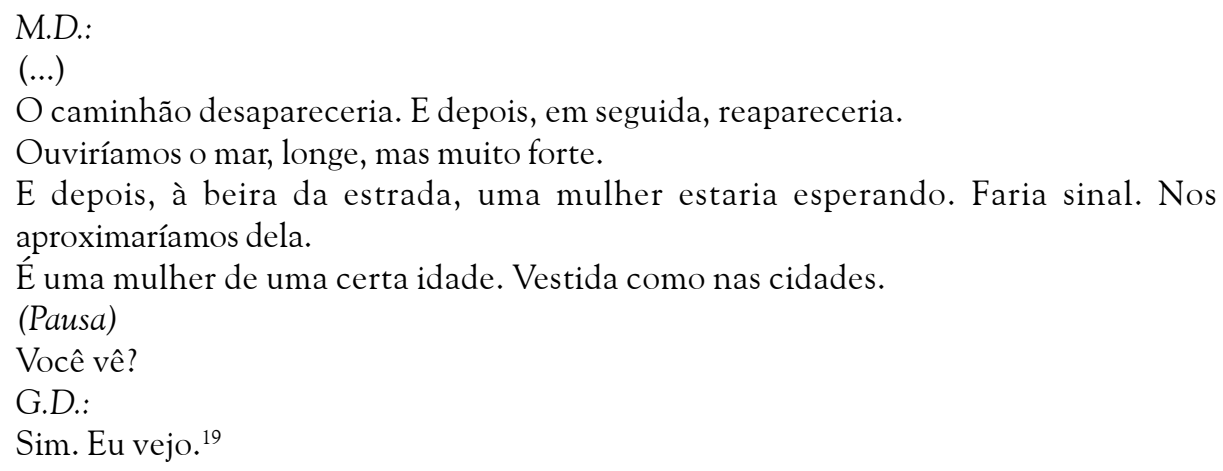

Assim como Depardieu, nós tambem podemos ver - a imagem nos é dada, como a ele, pelas palavras. A imagem é lançada para o exterior, para um plano que a

\footnotetext{
${ }^{15}$ Duras. Entretien avec Michelle Porte, p.89.

${ }^{16}$ Cf. Blanchot. La bête de Lascaux, p.20.

${ }^{17}$ Duras, Porte. Les lieux de Marguerite Duras, p.94.

${ }^{18}$ Duras. Le camion, p.11-2.

${ }^{19}$ Duras. Le camion, p. 12.
} 
fotografia do filme já não pode apreender. O cinema de Duras quer fazer-se exatamente nesse fora, nesse limite da própria linguagem, no gesto de assinalar as coisas negativamente, como se, de fato, só assim a "essência" das coisas pudesse ser assinalada. Certamente isso nos revela também o risco implicado nesse gesto, nesse cinema: ele caminha para sua perda. Talvez, num relato de Duras sobre as filmagens de Le camion, possamos entrever esse cinema:

Tenho uma recordação inesquecível de Le camion. Numa noite, Depardieu tinha partido e contei a história do parto da mãe do pequeno Abraham, da filha da mulher do caminhão. A imagem parou, filmávamos com rolos de 120 metros e o operador me fez sinal para continuar; e vi toda a equipe escutando a narrativa, preferindo não me cortar para escutarem, eles, toda a narrativa, para terem, eles, toda a narrativa, a título pessoal, ao invés de me cortarem e recomeçarmos. Jamais esquecerei isso. Eles preferiram me deixar continuar - era muito cruel: depois, não fiquei contente — ao invés de se privarem, eles, do fim da narrativa. Depois, voltei a pensar nisso. Acho formidável que uma equipe ouse fazer isso. Bruno me fez sinal: continue. Continuei. Somente depois de três, quatro minutos, compreendi que a câmara não estava mais filmando. Foi como se a equipe se tornasse livre. ${ }^{20}$

Certamente o que fascina Duras no gesto ousado da equipe é a possibilidade cruel de o cinema lançar-se para além (ou aquém) do filme, de ele permanecer como o texto do filme - em sua forma condicional, literalmente imaginária. E é aí, nesse ponto, que se faz o cinema, que ele deve atravessar a sua irrealidade e fazer-se, pois para Duras "a fabricação do filme já é o filme". ${ }^{21}$

Ainda que não exista, ainda que não o tenha encontrado, esse cinema, Duras o fez. Mesmo que o tenha procurado como uma forma bastarda ou majestosa de escrita, quando as palavras eram por demais excessivas, mesmo que estivesse sempre disposta a abandoná-lo para reencontrar nele não o cinema, mas a escrita e seu silêncio, Duras pôde legar-lhe o desejo de uma "imagem pura", aquela alcançada "por meio de uma escrita que modifica o fazer cinematográfico no seu próprio interior". ${ }^{22}$ Pois escrever acaba por se tornar esse cinema sem imagens, fissurado por um negro que rasga nele o filme, da mesma forma que o cinema converte-se num devir da escrita, na aproximação lenta e gradativa de seu acidente, seu desastre. Assim:

Silêncio.

O caminhão desapareceu.

A imagem desaparece. O NEGRO do fim começa (dezesseis segundos de negro).

Voz em off de M.D.:

Espera-se o acidente que vai povoar a floresta.

É o barulho de uma passagem.

Não se sabe de quem, de quê.

Silêncio.

E depois isso cessa. ${ }^{23}$

\footnotetext{
${ }^{20}$ DuRAs. Entretien avec Michelle Porte, p.98.

${ }^{21}$ DuRAs. Deuxième projet, p.77.

${ }^{22}$ Guimarães. Imagens da memória, p.196.

${ }^{23}$ Duras. Le camion, p.70.
} 
Sabendo, por fim, que caminhar "para a sua perda é o único cinema", "é a única política" ${ }^{24}$ da arte, sonhemos, aqui, com a sua impossibilidade. Com o barulho negro de sua passagem. Sim.

\title{
(4)
}

\begin{abstract}
A B S TRACT
Almost unknown to the majority of the public, Marguerite Duras's cinematographic work establishes intricate relationships with her literary work as it promotes the undistinguishability of one creative field from the other, without, nevertheless, instituting any kind of hierarchy between both. The creation process of the film Le camion (1977) points to other possibilities in the understanding of cinema and literature.
\end{abstract}

\section{KEY - WORDS}

Marguerite Duras, writing, cinema

\section{REFERÊNCIAS BIBLIOGRÁFICAS}

Blanchot, Maurice. L'entretien infini. Paris: Gallimard, 1959.

Blanchot, Maurice. La bête de Lascaux. Paris: Fata Morgana, 1982.

Blanchot, Maurice. O livro por vir. Trad. Maria Regina Louro. Lisboa: Relógio d'Água, 1984.

Blanchot, Maurice. A parte do fogo. Trad. Ana Maria Scherer. Rio de Janeiro: Rocco, 1997.

DurAs, Marguerite. Le camion. Paris: Minuit, 1977.

Duras, Marguerite. Deuxième projet. In: Le camion. Paris: Minuit, 1977. p.75-7.

DurAs, Marguerite. Écrire. Paris: Gallimard, 1993.

Duras, Marguerite. Entretien avec Michelle Porte. In: Le camion. Paris: Minuit, 1977. p.83-136.

DurAs, Marguerite. Premier projet. In: Le camion. Paris: Minuit, 1977. p.73-4.

DurAs, Marguerite. Le vice-consul. In: Roman, cinéma, théâtre, un parcours (1943-1994). Paris: Gallimard, 1997. p.845-964.

DuRAs, Marguerite. La vie matérielle. Marguerite Duras parle à Jérôme Beaujour. Paris: Gallimard, 2001.

Duras, Marguerite. Les yeux verts. Paris: Cahiers du Cinéma, 1987.

Duras, Marguerite, Porte, Michelle. Les lieux de Marguerite Duras. Paris: Éditions de Minuit, 1977.

Guimarães, César. Imagens da memória: do legível ao visível. Belo Horizonte: UFMG, 1997.

${ }^{24}$ DuRAS. Premier projet, p.74. 